Running Head: SCHADENFREUDE AND GLÜCKSCHMERZ AS COUNTEREMPATHIC EMOTIONAL REGULATORS

\title{
Empathetic Failures of Schadenfreude and Glückschmerz in Social Contexts
}

\author{
Edward Thomas
}

Hinsdale South High School 


\begin{abstract}
Despite their evolutionary and social drawbacks, humans (as well as many other animals) tend to wish the best for those they like and associate with while feeling resentful against others. Here, the potential neurological basis behind schadenfreude (pleasure in one's pain) and glückschmerz (pain in one's pleasure) and their behavioral implications, especially in social settings, are reviewed and a new wave of conversation in the field to promote the utilization of novel groups in real-world situations to eliminate pre-existing biases, notions, and other potentially confounding factors as well as promote research in glückschmerz as a whole is encouraged to spark new understandings in how schadenfreude and glückschmerz may play out in our day-to-day lives.
\end{abstract}

Keywords: Schadenfreude, Glückschmerz, Counter-Empathy, Emotion, Interpersonal Interaction 


\section{Highlights:}

- Schadenfreude and Glückschmerz are counter-empathic emotions that can be understood as a pleasure in another's pain and a pain in another's pleasure, respectively.

- Schadenfreude and Glückschmerz are social regulators but can invoke blind-sightedness when occurring within and between ingroups and outgroups leading to poor long-term consideration of consequences and dehumanization of the outgroup.

- Current research efforts on social counter-empathy focus on pre-existing or historically assigned groups that may lead to over-generalization in assumptions of behavior.

- Future research must utilize novel groups in real social settings to better represent counter-empathic behavior and draw more accurate conclusions about social threat and behavior. 


\section{Introduction}

As humans evolved, we inherently depended on each other to survive. We relied on favors, obligations, and others to help guide us through the world we lived in. As such, humans came to develop what are called pro-social behaviors. Pro-social behaviors involve a give-and-take in relationships that encourage future giving-and-taking and thereby increase our sense of companionship and reliance on each other.

Empathy, the ability to reciprocate emotions between people, has long been theorized (Davis, 2018) to have originated as a form of prosocial behavior - allowing us to partake in another's emotional state and relate to them. This would've helped forge stronger bonds between humans and allowed us to reap the benefits of having a support system and, therefore, a greater chance of survival.

The power of empathy, though now less of a biological than a social necessity, continues to exist in today's society as a powerful predictor of supportive behavior within groups (Stürmer et al., 2005; see Sylvia et al., 2014). However, despite this innate tendency, humans tend to experience remarkably antisocial, yet rarely studied (Yang et al., 2020) behavior in the form of schadenfreude and glückschmerz (Smith \& van Dijk, 2018; Smith, Powell, et al., 2009). 


\section{Schadenfreude and Glückschmerz}

Schadenfreude comes from the combination of two German words - Schaden (meaning harm) and Freude (meaning joy) (Yang et al., 2020). Schadenfreude is why we might laugh when someone trips or does something "stupid" and messes up. It can best be described as a pleasure at another's misfortune or pain (which can be understood as a form of gloating (Simone et al., 2007). Glückschmerz, another German word, is the double opposite to schadenfreude (van de Ven, 2018) and describes pain at another's fortune or pleasure.

\section{Neural and Physiological Basis of Schadenfreude and Glückschmerz}

Schadenfreude and glückschmerz appear to have evolved to be ingrained into our neural pathways, despite anti-social behaviors being less conducive to survival in a group. Similar brain activity occurs in the anterior cingulate cortex and anterior insula when both one's side loses and when an opposing side wins (schadenfreude). Similar activity has also been found in the ventral striatum when both one's side wins and the other's loses (schadenfreude) (Cikara, Botvinick \& Fiske, 2011) suggesting that there may be an evolutionary context behind such counter-empathic emotions.

Even when both parties lose or win something, the relativity of that loss or gain is enough to elicit schadenfreude and glückschmerz in response in the Ventral Striatum (Dvash et al., 2010).

Additionally, the oxytocinergic system appears to contribute to Schadenfreude and Envy as well. Oxytocin, specifically, increases envy in relative-loss situations where others gain more than the individual (glückschmerz) and can increase gloating when others gain less than the individual in question (schadenfreude) (Shamay-Tsoory, 2009). 


\section{Evolutionary Purpose of Schadenfreude}

Emotions are the response to threats or changes in one's environment and help us to react and deal with this chance or threat accordingly (van de Ven, 2018). Proposals of why we may have evolved to have pathways that allow us to experience schadenfreude and glückschmerz vary but generally suggest that they may be the result of a response to imbalances between our perceptions of others and where they actually are in comparison (van de Ven, 2018). As we naturally want to settle imbalances, schadenfreude and glückschmerz help to emotionally signal to us that this imbalance should be addressed (van de Ven, 2018). These imbalances are usually based on an assumption that we are being treated unfairly in some way and schadenfreude and glückschmerz cause us to have an emotional response and therefore attempt to fix the inequality (someone who gets everything should suffer a bit (schadenfreude) and someone who we see poorly shouldn’t feel good (glückschmerz)) (van de Ven, 2018).

Therefore, glückschmerz could be viewed as the result for a need for a signal for attention to be given to resolve some sort of imbalance while schadenfreude could be seen as a way for us to note that everything is okay now, and we can pursue something else (van de Ven, 2018).

Expressing schadenfreude also serves to prevent individuals from asserting an excessive amount of dominance in group settings (Lange \& Boecker, 2019) likely through the imbalance that schadenfreude originates from and our desire to quell it.

\section{Societal Implications of Schadenfreude}

Although schadenfreude has an important function in ensuring societal balance, when it is elicited between two opposing groups, it has to potential of getting out-of-hand. When an opposing party makes a mistake and causes damage or loss to property, schadenfreude is evoked 
in the former party despite the potential for the implications of the other party's actions to cause harm to the former party down-the-road (by negatively impacting the economy or themselves) (David et al., 2009). This could point toward schadenfreude (and thereby similarly glückschmerz) being so rewarding that -- even if the result may harm us or society in the long run -- our actions, reactions, and thoughts continue to be influenced by schadenfreude.

This "craving" for the immediate, instantaneous gratification of schadenfreude at the expense of anti-social behavior instead of thinking critically could lead to our judgment becoming cloudy and us lacking full awareness of the consequences that our own or others' actions can bring. The dangers of our "blind craving" for schadenfreude can not only be dangerous in the long run but, through associating someone else's pain with a sort of subjective pleasure, may even allow people to become "numb" to their antisocial behavior (Cikara, 2015).

\section{Factors Contributing to the Elicitation of Schadenfreude}

Among the several factors that contribute to schadenfreude, envy is perhaps the most notable. The Stereotype Content Model suggests that we judge people based on their competence and their projected warmth and proposes that envy is a response to others whose stereotypes denote status and competitiveness (see Fiske et al., 2002). These stereotypes elicit schadenfreude, especially when people with a higher status and who are uncooperative experience misfortunes than when lower-status individuals who are more cooperative face similar misfortunes (Cikara \& Fiske, 2012; see Takahashi et al., 2009). Granted, this effect appears to nearly disappear when both lower-status and high-status individuals are seen as deserving of the misfortune (Dasborough \& Harvey, 2017; see Smith, Powell, et al., 2009). This can be extended into the workplace where perceived errors of low-severity from a CEO are 
significantly more likely to induce schadenfreude than if from an employee (Dasborough \& Harvey, 2017).

Similarly, low self-esteem is connected with highly hostile behavior and attitudes -- like schadenfreude (Yang et al., 2020) -- possibly because these individuals tend to feel more threatened by the unfavorable actions of others (Rentsch et al., 2015) and seek to quell this psycho-emotional imbalance and feel more self-confident (Brambilla \& Riva, 2017).

A sense of inferiority in status and/or competitiveness may also cause us to form strong negative associations against the group that makes us feel inferior and may lead us to become more inclined to rejoice over that outgroup's failures (Leach et al, 2003; Takahashi et al., 2009).

\section{Schadenfreude and Glückschmerz in Group Formation}

Forming a group can be a powerful method of sharing ideas --- but when schadenfreude and glückschmerz are in play, it can lead to dangerous consequences because of the nature of the group-forming process. An integral part of choosing a group is by judging a group's "entitativity". Group entitativity is a property of cohesive, connected, and systematic groups (Pereira \& van Prooijen, 2018) that often revolve around connecting over similar ideologies or beliefs. Humans inherently most value groups with high levels of entitativity (Lickel et al., 2000) and can even go as far as being willing to endure pain for those in their group (Montalan et al., 2012; Hein et al., 2010).

But, in this process of creating an inviting, cohesive bond with those who are in a group, ingroup members develop strong ingroup-outgroup bias (Mullen et al., 1992) -- leading to an increase in schadenfreude (Hoogland et al., 2015), dehumanization, a stronger sense of aggression (Struch et al, 1989), and a lack of empathy (Chang et al., 2016) towards outgroups 
that don't align with their values or traits (Symbolic Threat Theory (Kinder, 1981)), those they see as competition (Realistic Group Conflict Theory (Sherif, 1966)), and those that they perceive as potentially threatening (Esses et al., 1998).

Not only that, but members of a group are also far more likely to turn a blind eye towards the actions of those in their group than those of an outgroup member doing the same thing (Pereira, Falomir-Pichastor, et al., 2015).

And, because outgroup members are seen as relatively homogeneous (Brauer, 2001), ingroup members developing a strong sense of schadenfreude, glückschmerz, and intergroup threat in response to a whole outgroup because of one member's actions.

This schadenfreude can then develop into a positive-feedback loop as continuous schadenfreude against a group results in constant degradation of the outgroup where they are further villainized and dehumanized making them targets for further degradation (Yang et al., 2020).

This pleasure that becomes associated with an outgroup's pain (schadenfreude) can lead to an increased chance of violence against outgroups (Cikara, 2015) as the anterior insula's activation is connected with a willingness to harm outgroups (Cikara \& Fiske, 2011). Ingroup members also become remorseless -- feeling schadenfreude when an opposing team member suffers an injury and glückschmerz when that person recovers no matter how serious or how painful it would be to that person (Hoogland et al., 2015). This violence has the potential to generalize to those who are not directly related to the outgroup and who have yet to provoke reasonable harm to the ingroup (Cikara, 2015) --- even if they are not completely against the ingroup's qualities and beliefs. In one study, Americans with a larger empathy gap between themselves and Arabs were also less likely to donate to Arab charities (Bruneau et al., in press) -- 
indicating that schadenfreude and glückschmerz may also be a large predictor of decreased pro-social behavior (see Johnson et al., 2002).

\section{Errors in Generalized Assumptions of Behavior}

Current research places emphasis on the group entitativity, intergroup threat, pro-social behavior, empathy bias, schadenfreude, and glückschmerz between already-established or historically-assigned groups (Cikara, Bruneau, et al., 2014) such as opposing political parties (David eet al., 2009), sports teams (Leach et al., 2003; Hoogland et al, 2015), and racial groups (Montalan et al, 2012; Johnson et al., 2002; Xu et al., 2009; Mathur et al., 2010).

However, conclusions from such research can lead to generalized assumptions of ingroup-outgroup behavior.

For instance, when White individuals were shown the faces of Whites and Asians while their hands were pricked, White individuals showed greater neural activity in areas associated with pain in response to White people's hands being pricked over when Asians' hands were (Xu et al., 2009).

From this, a general assumption could be created - that an empathy-bias often exists between individuals of racially-divided groups. In other words, counter-empathy exists when an individual interacts with a race they don't relate to (from a racially-divided context).

However, in another study, when Whites were shown the faces of Whites vs Blacks while their hands were being pricked, White individuals showed similar neural activity in areas associated with pain for both groups (Mathur et al., 2010). These two scenarios point towards there possibly being other factors to pain empathy than simply ingroup-outgroup bias and empathy bias. 


\section{Discrimination as a Byproduct of Intergroup Threat}

Such factors could include the stereotypically competitive and high-status threat that Asians are seen with when they have become fortunate. This can activate the anterior insula (associated with pain) to an outsider (Cikara \& Fiske, 2011) --- possibly attributable to Realistic Group Conflict Theory.

Similarly, people are more likely to be seen as black than white when confronted with economic threats (Ho et al., 2013; Krosch \& Amodio, 2014) and characterized by stereotypically-defined blackness and darker skin (Chang et al., 2016) by white individuals. The danger of this is that blackness and a darker skin tone are closely related to the risk of discrimination (Maddox, 2004). This discrimination may then lead people characterized as black to be rejected resources or help as a means to prevent danger to an ingroup member by an outgroup (Chang et al., 2016; Krosch \& Amodio, in press). 


\section{Discussions}

Utilization of Novel Groups as a Method of Preventing Generalized Assumptions of Pro-Social Behavior in the Group Setting

To forgo many of the complications that arise with pro-social research into already-established/historically-assigned groups, it's proposed that group entitativity, intergroup threat, empathy bias, schadenfreude, and glückschmerz be analyzed using novel groups (Cikara, Bruneau, et al., 2014). The usage of novel groups has been shown to still give validatable findings provided that there is some form of competition between these novel groups (Chang et al., 2016). Novel groups are particularly useful to analyze and review previously-assumed statements of relations between already-established or historically-assigned groups as even in novel groups, people can experience ingroup-outgroup bias for someone's pain and pain judgments (Montalan et al., 2012). This could be especially beneficial when looking into our desire for and resistance to malignancy as being able to empathize with pain is a remarkably strong indicator of pro-social attitude and behavior (Sylvia et al., 2014)

Forming novel groups to eliminate potentially-confounding factors of these behaviors can even be applied to studies of children and their formation of social groups (see Masten et al., 2010).

\section{Utilization of Real Social Environments to Reflect Real Experiences and Prevent Generalization and Promote Further Validity}

Current research into envy and schadenfreude focuses on the usage of vignette studies and more theoretical situations (Yang et al., 2020) to find trends in social behavior and emotional response. However, judging situations that are not necessarily happening in front of one's eyes brings up 
concerns as to just how valid the results may. Therefore, it's proposed that rather social behavioral and emotional responses be studied in real-world scenarios where participants are interacting with themselves in the situation to more accurately elicit the emotional and behavioral responses to others' actions.

\section{Lack of Glückschmerz Testing}

In comparison to schadenfreude, there appears to be a profound lack of research into glückschmerz. Though research into schadenfreude is key to understanding antisocial behavior and the processes of envy, it is also important to consider researching glückschmerz as an emotion as it too shows an important part of our antisocial personality that would benefit from further research. 


\section{Conclusions}

Despite its pro-social roots, empathy has evolved to become a dangerous proponent to our judgments, reasonings, and group tendencies. However, to better be able to understand the finer processes that group entitativity, intergroup threat, pro-social behaviors, and empathy -- amongst others -- play on schadenfreude and glückschmerz, it's vital to continue exploring their

implications in novel group settings while exploring the influence of various factors and environments on our perception and desire to rejoice in another's failures and grieve in one another's happiness. 


\section{References}

Brauer, Markus. (2001). Intergroup Perception in the Social Context: The Effects of Social Status and Group Membership on Perceived Out-group Homogeneity and Ethnocentrism. Journal of Experimental Social Psychology - J EXP SOC PSYCHOL. 37. 15-31. 10.1006/jesp.2000.1432.

Bruneau EG, Cikara M, Saxe R: Intergroup empathy bias, not trait empathic concern, predicts out-group altruism. In press

Chang, L. W., Krosch, A. R., \& Cikara, M. (2016). Effects of intergroup threat on mind, brain, and behavior. Current Opinion in Psychology, 11, 69-73.

Cikara, M., Botvinick, M. M., \& Fiske, S. T. (2011). Us versus them: social identity shapes neural responses to intergroup competition and harm. Psychological science, 22(3), 306-313. https://doi.org/10.1177/0956797610397667

Cikara, M., \& Fiske, S. T. (2012). Stereotypes and Schadenfreude: Affective and physiological markers of pleasure at outgroup misfortunes. Social psychological and personality science, 3(1), 10.1177/1948550611409245. https://doi.org/10.1177/1948550611409245

Cikara, M., Bruneau, E., Van Bavel, J. J., \& Saxe, R. (2014). Their pain gives us pleasure: How intergroup dynamics shape empathic failures and counter-empathic responses. Journal of experimental social psychology, 55, 110-125. https://doi.org/10.1016/j.jesp.2014.06.007

Cikara, M. (2015). Intergroup schadenfreude: Motivating participation in collective violence. Current opinion in behavioral sciences, 3, 12-17.Chicago 
Cikara M, Fiske ST: Bounded empathy: neural responses to outgroup targets' (mis)fortunes. J Cogn Neurosci 2011, 23:3791-3803

Dasborough, M., Harvey, P. Schadenfreude: The (not so) Secret Joy of Another's Misfortune. $J$ Bus Ethics 141, 693-707 (2017). https://doi.org/10.1007/s10551-016-3060-7

David J.Y. Combs, Caitlin A.J. Powell, David Ryan Schurtz, Richard H. Smith, Politics, schadenfreude, and ingroup identification: The sometimes happy thing about a poor economy and death, Journal of Experimental Social Psychology, Volume 45, Issue 4, 2009, Pages 635-646, ISSN 0022-1031, https://doi.org/10.1016/j.jesp.2009.02.009.(https://www.sciencedirect.com/science/article/ pii/S0022103109000407)

Davis, M. H. (2018). Empathy: A social psychological approach. Routledge.Chicago

Dvash, J., Gilam, G., Ben-Ze'ev, A., Hendler, T. and Shamay-Tsoory, S.G. (2010), The envious brain: The neural basis of social comparison. Hum. Brain Mapp., 31: 1741-1750. https://doi.org/10.1002/hbm.20972

Esses VM, Jackson LM, Armstrong TL: Intergroup competition and attitudes toward immigrants and immigration: an instrumental model of group conflict. J Soc Issues 1998, $54: 699-724$.

Fiske, S. T., Cuddy, A. J., Glick, P., \& Xu, J. (2002). A model of (often mixed) stereotype content: competence and warmth respectively follow from perceived status and competition. Journal of personality and social psychology, 82(6), 878-902. 
SCHADENFREUDE AND GLÜCKSCHMERZ AS COUNTEREMPATHIC EMOTIONAL REGULATORS

Hein, G., Silani, G., Preuschoff, K., Batson, C. D., \& Singer, T. (2010). Neural responses to ingroup and outgroup members' suffering predict individual differences in costly helping. Neuron, 68(1), 149-160. https://doi.org/10.1016/j.neuron.2010.09.003

Ho AK, Sidanius J, Cuddy AJ, Banaji MR: Status boundary enforcement and the categorization of black-white biracials. J Exp Soc Psychol 2013, 49:940-943.

Hoogland, C.E., Ryan Schurtz, D., Cooper, C.M. et al. The joy of pain and the pain of joy: In-group identification predicts schadenfreude and gluckschmerz following rival groups' fortunes. Motiv Emot 39, 260-281 (2015). https://doi.org/10.1007/s11031-014-9447-9

Johnson, J.D., Simmons, C.H., Jordav, A., Maclean, L., Taddei, J., Thomas, D., Dovidio, J.F. and Reed, W. (2002), Rodney King and O. J. Revisited: The Impact of Race and Defendant Empathy Induction on Judicial Decisions. Journal of Applied Social Psychology, 32: 1208-1223. https://doi.org/10.1111/j.1559-1816.2002.tb01432.x

Kinder, D. R., \& Sears, D. O. (1981). Prejudice and politics: Symbolic racism versus racial threats to the good life. Journal of Personality and Social Psychology, 40(3), 414-431. https://doi.org/10.1037/0022-3514.40.3.414

Krosch AR, Amodio DM: Economic scarcity alters the perception of race. Proc Nat Acad Sci 2014, 111:9079-9084

Krosch AR, Amodio DM: Perceptual dehumanization of Black faces promotes racial discrimination under economic stress. In press

Lange, J., \& Boecker, L. (2019). Schadenfreude as social-functional dominance regulator. Emotion, 19(3), 489-502. https://doi.org/10.1037/emo0000454 
Leach, C. W., Spears, R., Branscombe, N. R., \& Doosje, B. (2003). Malicious pleasure: schadenfreude at the suffering of another group. Journal of personality and social psychology, 84(5), 932-943. https://doi.org/10.1037/0022-3514.84.5.932

Lickel, B., Hamilton, D. L., Wieczorkowska, G., Lewis, A., Sherman, S. J., \& Uhles, A. N. (2000). Varieties of groups and the perception of group entitativity. Journal of personality and social psychology, 78(2), 223-246. https://doi.org/10.1037//0022-3514.78.2.223

Maddox KB: Perspectives on racial phenotypicality bias. Pers Soc Psychol Rev 2004, 8:383-401.

Masten, C. L., Gillen-O'Neel, C., \& Brown, C. S. (2010). Children's intergroup empathic processing: the roles of novel ingroup identification, situational distress, and social anxiety. Journal of experimental child psychology, 106(2-3), 115-128. https://doi.org/10.1016/j.jecp.2010.01.002

Mathur, V. A., Harada, T., Lipke, T., \& Chiao, J. Y. (2010). Neural basis of extraordinary empathy and altruistic motivation. NeuroImage, 51(4), 1468-1475. https://doi.org/10.1016/j.neuroimage.2010.03.025

Montalan, B., Lelard, T., Godefroy, O., \& Mouras, H. (2012). Behavioral investigation of the influence of social categorization on empathy for pain: a minimal group paradigm study. Frontiers in psychology, 3, 389. https://doi.org/10.3389/fpsyg.2012.00389

Mullen, B., Brown, R. and Smith, C. (1992), Ingroup bias as a function of salience, relevance, and status: An integration. Eur. J. Soc. Psychol., 22: 103-122. https://doi.org/10.1002/ejsp.2420220202 
Pereira, A., Falomir-Pichastor, J. M., Berent, J., Staerklé, C. and Butera, F. (2015), In the name of democracy: The value of democracy explains leniency towards wrongdoings as a function of group political organization. Eur. J. Soc. Psychol., 45: 191-203. doi: 10.1002/ejsp.2081.

Pereira, A., van Prooijen JW. Why we sometimes punish the innocent: The role of group entitativity in collective punishment. PLoS One. 2018;13(5):e0196852. Published 2018 May 3. doi:10.1371/journal.pone.0196852

Shamay-Tsoory, S. G., Fischer, M., Dvash, J., Harari, H., Perach-Bloom, N., \& Levkovitz, Y. (2009). Intranasal administration of oxytocin increases envy and schadenfreude (gloating). Biological psychiatry, 66(9), 864-870. https://doi.org/10.1016/j.biopsych.2009.06.009

Sherif M: Group Conflict and Co-operation: Their Social Psychology. Routledge \& K. Paul; 1966

Simone G. Shamay-Tsoory, Yasmin Tibi-Elhanany, Judith Aharon-Peretz, The green-eyed monster and malicious joy: the neuroanatomical bases of envy and gloating (schadenfreude), Brain, Volume 130, Issue 6, June 2007, Pages 1663-1678, https://doi.org/10.1093/brain/awm093

Smith, R.H., Powell, C.A.J., Combs, D.J.Y. and Schurtz, D.R. (2009), Exploring the When and Why of Schadenfreude. Social and Personality Psychology Compass, 3: 530-546. https://doi.org/10.1111/j.1751-9004.2009.00181.x

Smith, Richard \& van Dijk, Wilco. (2018). Schadenfreude and Gluckschmerz. Emotion Review. 10. $175407391876565.10 .1177 / 1754073918765657$. 
Struch, N., \& Schwartz, S. H. (1989). Intergroup aggression: its predictors and distinctness from in-group bias. Journal of personality and social psychology, 56(3), 364-373. https://doi.org/10.1037//0022-3514.56.3.364

Stürmer, S., Snyder, M., \& Omoto, A. M. (2005). Prosocial emotions and helping: the moderating role of group membership. Journal of personality and social psychology, 88(3), 532-546. https://doi.org/10.1037/0022-3514.88.3.532

Sylvia A. Morelli, Lian T. Rameson, Matthew D. Lieberman, The neural components of empathy: Predicting daily prosocial behavior, Social Cognitive and Affective Neuroscience, Volume 9, Issue 1, January 2014, Pages 39-47, https://doi.org/10.1093/scan/nss088

Takahashi, H., Kato, M., Matsuura, M., Mobbs, D., Suhara, T., \& Okubo, Y. (2009). When your gain is my pain and your pain is my gain: neural correlates of envy and schadenfreude. Science (New York, N.Y.), 323(5916), 937-939. https://doi.org/10.1126/science.1165604

van de Ven, N. (2018). Schadenfreude and Gluckschmerz Are Emotional Signals of (Im)Balance. Emotion Review, 10(4), 305-306. https://doi.org/10.1177/1754073918768883

Xu, X., Zuo, X., Wang, X., \& Han, S. (2009). Do you feel my pain? Racial group membership modulates empathic neural responses. The Journal of neuroscience : the official journal of the Society for Neuroscience, 29(26), 8525-8529. https://doi.org/10.1523/JNEUROSCI.2418-09.2009 
Yang, L., Cropanzano, R., Daus, C., \& Martínez-Tur, V. (Eds.). (2020). The Cambridge Handbook of Workplace Affect (Cambridge Handbooks in Psychology). Cambridge: Cambridge University Press. doi:10.1017/9781108573887 